\title{
Retraction Note to: Urban groundwater pollution and green city economic efficiency based on image recognition
}

Jia $\operatorname{Tian}^{1}$

Published online: 15 November 2021

(c) Saudi Society for Geosciences 2021

Retraction Note to: Arabian Journal of Geosciences (2021) 14: 1567 https://doi.org/10.1007/s12517-021-07716-w

The Editor-in-Chief and the Publisher have retracted this article because the content of this article is nonsensical. The peer review process was not carried out in accordance with the Publisher's peer review policy. The author has not responded to correspondence regarding this retraction.

The original article can be found online at https://doi.org/10.1007/ s12517-021-07716-w.

Jia Tian

tj2021001@163.com

1 Henan Polytechnic, Zhengzhou 450000, Henan, China 